\title{
PENURUNAN KANDUNGAN RESIDU INSEKTISIDA DIMETOAT DALAM CABAI MERAH (Capsicum annum L.) AKIBAT IRADIASI GAMMA
}

\author{
SOFNIE M CHAIRUL, ACHMAD NASROH KUSWADI \\ Pusat Aplikasi Teknologi Isotop dan Radiasi (PATIR) BATAN, \\ Jl. Lebak Bulus Raya No 49 Jakarta 12440 \\ Tlp.021.7690709. Faks 7691607
}

\begin{abstract}
Abstrak
PENURUNAN KANDUNGAN RESIDU INSEKTISIDA DIMETOAT DALAM CABAI MERAH (Capsicum annum L.) AKIBAT IRADIASI GAMMA. Produk sayuran, seperti cabai merah, dipersyaratkan untuk mendapat perlakuan karantina sebelum diekspor, misalnya dengan cara iradiasi gamma yang ditujukan untuk membunuh hama dan penyakit tanaman yang mungkin dikandungnya. Selain mengandung hama dan penyakit, cabai yang dipanen sering pula mengandung residu insektisida, sehingga perlu diamati pengaruh iradiasi gamma terhadap residu insektisida yang dikandungnya. Cabai merah keriting (Capsicum annum L) direndam dengan insektisida dimetoat pada konsentrasi 100; 200; dan 300 ppm. Kandungan residu insektisida kemudian dianalisis menggunakan kromatografi gas pada cabai merah sebelum penyimpanan, setelah penyimpanan selama 7 hari, serta setelah perlakuan iradiasi sinar gamma pada dosi 0,5 ; 1,0; dan 1,5 kGy. Hasil penelitian menunjukkan bahwa kandungan residu insektisida dimetoat pada cabai merah keriting dengan perlakuan penyimpanan pada suhu $5{ }^{\circ} \mathrm{C}$ selama 1 minggu menunjukkan penurunan sebesar antara 3,94 \% - 24,13\%. Jika diiradiasi dengan sinar $-\gamma$ pada dosis $0,5 \mathrm{kGy}$ terjadi penurunan sebesar antara $6,61 \%-28,18 \%$, dan jika diiradiasi pada dosis 1,0 kGy maka penurunan menjadi antara 10,20\% - 43,26\%, dan pada dosis $1,5 \mathrm{kGy}$ penurunan menjadi antara $18,57 \%-54,00 \%$.
\end{abstract}

Kata kunci: Insektisida dimetoat, Capsicum annum L, irradiasi, sinar $-\gamma$

\begin{abstract}
REDUCTION OF INSECTICIDE RESIDUE CONCENTRATION OF DIMETOAT IN RED PEPPER Capsicum annum L. DUE TO GAMMA IRRADIATION. Horticultural product, such as red pepper, require a quarantine treatment, i.e using gamma irradiation, for disinfection of possible pest and diseases in the commodity. Besides containing pest and diseases, however, red pepper might also contain insecticide residue. Therefore, observation on the effect of gamma irradiation on the residue in red pepper is also needed in addition to the controlling of pests and diseases. Red pepper were soaked in dimethoate insecticide solution at concentration of 100;200; and 300 ppm, Residues of dimethoate insecticide in Capsicum annum L. were then analysed using gas chromatography immediately after treatment, 7 days after treatment and following irradiation with $\gamma$ - ray $(0.5 \mathrm{kGy} ; 1.0 \mathrm{kGy}$, and $1.5 \mathrm{kGy}$ dose $)$. The result showed that following 7 days incubation in the $5 \mathrm{oC}$ storage, dimethoate insecticide residues decreased $3.94 \%-24.13 \%$. Irradiation using $0.5 \mathrm{kGy}$ decreased the content of residues $6.61 \%$ -
\end{abstract}


$28.18 \%$, at $1.5 \mathrm{kGy}$ the residue decreased $10.20 \%-43.26 \%$ and at $1.5 \mathrm{kGy}$ the residues decreased $18.57 \%-54.00 \%$.

Keywords : Dimethoate, Insecticides, Capsicum annuum L., irradiation, $\gamma$ - ray

\section{PENDAHULUAN}

Salah satu pemanfaatan teknik nuklir dalam bidang pertanian dan pangan adalah penggunaan sinar gamma untuk meradiasi bahan pangan dan produk-produk pertanian lainnya. Iradiasi terhadap komoditi pertanian dapat dilakukan untuk tujuan pengawetan makanan, ${ }^{[1]}$ atau untuk membunuh hama dan penyakit yang mungkin masih terkandung dalam tanaman untuk tujuan karantina, menjaga kebersihan serta kesehatan tanaman (sanitary and phytosanitary). ${ }^{[2,3]}$ Masyarakat awam telah lama meragukan keamanan penggunaan iradiasi gamma untuk bahan pangan, namun sejak tahun 1997 Badan Pangan Dunia (WHO) telah menyatakan bahwa teknik ini aman untuk digunakan. ${ }^{[4]}$

Cabai (Capsicum annuum L.) adalah tanaman sayuran penting di Indonesia. Selain untuk memenuhi kebutuhan dalam negeri produk cabai merah juga diekspor. Di lapangan tanaman ini sering diserang oleh berbagai jenis hama seperti ulat buah (Heliothis armigera Hubner), kepik pengisap buah (Empoasca lybica de Bergevin), kepik hijau (Nezara viridula L.), ulat grayak (Spodoiptera litura Fabricus), lalat buah (Bactrocera dorsalis Hendel), trips (Thrips parvipinus Karny) dan tungau kuning (Polyphagotarsonemus latus Banks). ${ }^{[5,6]}$ Petani harus mengendalikan hama-hama ini untuk mempertahankan produksinya dan pada umumnya pengendalian dilakukan secara kimiawi dengan menyemprotkan insektisida. Insektisida yang biasa digunakan pada tanaman cabai adalah insektisida yang berasal dari golongan organofosfat, antara lain adalah dimetoat. Insektisida ini digunakan untuk mengendalikan hama kutu daun Myzus persicae dan hama Thrips sp.

Insektisida dimetoat bersifat sistemik dan racun kontak. Nama kimia dari dimetoat adalah O,O-dimetil S-metilcarbomoil metilfosforoditioat dengan rumus molekul $\mathrm{C}_{5} \mathrm{H}_{12} \mathrm{NO}_{3} \mathrm{PS}_{2}$ yang mempunyai bobot molekul 229,2 dan bentuk rumus bangun sebagai berikut: ${ }^{[7]}$<smiles>CNC(=O)CSP(=S)(OC)OC</smiles>

Gambar 1. Insektisida Dimetoat

Penggunaan pestisida terutama insektisida sudah dianjurkan oleh Pemerintah sejak tahun 70-an, dan penggunaannya pun telah diatur oleh Komisi pestisida. Departemen Pertanian sesuai dengan dosis yang tertentu. Pemerintah secara 
resmi telah menetapkan batas maksimum residu pestisida yang diperbolehkan dan terkandung pada hasil pertanian yang akan dikonsumsi oleh masyarakat. ${ }^{[8]}$ Berdasarkan hasil survey di lapangan para petani pada umumnya tidak lagi mengikuti aturan Pemerintah, mereka hanya melihat populasi serangga yang menyerang tanaman, sehingga mereka mengaplikasikan pestisida tersebut secara berulangkali dan bahkan pada saat panen pun mereka masih menyemprotkan pestisida tersebut. Dengan demikian, di dalam hasil panen tanaman cabai kemungkinan masih terdapat residu insektisida dimetoat.

Perlakuan karantina diperlukan apabila sayuran cabai akan di ekspor ke negara lain. Pengalaman menunjukkan bahwa, tanpa perlakuan karantina, paprika Indonesia ditolak untuk diekspor ke Taiwan karena dikawatirkan mengandung hama lalat buah yang dapat menular ke negara pengimpor. ${ }^{[9]}$ Salah satu cara perlakuan karantina adalah dengan iradiasi gamma. ${ }^{[10]}$

Selain mengandung hama dan penyakit yang harus diperlakukan dengan iradiasi, komoditi cabai juga mengandung residu insektisida, dalam penelitian ini diamati apakah dosis yang digunakan untruk perlakuan karantina selain membunuh hama penyakit juga menurunkan residu insektisida yang dikandungnya.

Untuk hal tersebut, maka dilakukan suatu penelitian simulasi, dimana cabai direndam dengan suatu larutan insektisida dimetoat, lalu diiradiasi dengan sinar gamma, kemudian dianalisis secara kimia untuk menentukan kandungan residu insektisida tersebut dengan membandingkannya terhadap sampel tanpa dilakukan iradiasi.

\section{METODE PENELITIAN}

\section{Bahan Penelitian}

Bahan yang digunakan dalam penelitian ini adalah cabai merah keriting yang diperoleh dari salah satu pasar tradisional di daerah jakarta timur. Sampel dipilih berdasarkan kesamaan ukuran.

\section{Perlakuan Pestisida Dimetoat pada Cabai Merah Keriting}

Cabai merah keriting direndam ke dalam larutan insektisida dimetoat dengan tiga macam dosis (100 ppm, 200 ppm dan 300ppm) selama 3 menit. Cabai kemudian diangkat dan dikeringkan dengan cara ditiriskan agar larutan dimetoat menjadi kering. Setelah itu cabai di dibagi menjadi 3 kelompok : langsung diekstraksi, disimpan selama 7 hari pada lemari pendingin dan disimpan selama 7 hari lalu diiradiasi pada dosis 0,$5 ; 1,0$; dan $1,5 \mathrm{kGy}$.

\section{Analisis Residu Pestisida Secara Kromatografi Gas}

Cabai merah keriting dipotong-potong kecil, lalu ditimbang sebanyak 50 gram ke dalam gelas piala, kemudian ditambahkan lebih kurang 50 gram $\mathrm{Na}_{2} \mathrm{SO}_{4}$ anhidris, 
lalu diaduk hingga homogen. Tambahkan $100 \mathrm{ml}$ larutan etil asetat, kocok dengan bamiks selama 3 menit, lalu didekadentir sampai terpisah antara pelarut dan ampas cabai. Larutan yang jernih dipipet sebanyak 10ml, dan langsung injeksikan pada Gas Kromatografi dengan menggunakan detektor ECD (Electron Capture Detektor), pada suhu kolom: $200^{\circ} \mathrm{C}$; Suhu injektor : $210^{\circ} \mathrm{C}$ dan suhu detektor $: 210^{\circ} \mathrm{C}$. Kolom berupa kapiler berisi 3\% OV-101 dalam kromosorb WAW

\section{HASIL DAN PEMBAHASAN}

Kandungan insektisida dimetoat dalam cabai merah keriting setelah perendaman dengan konsentrasi 100, 200, dan 300 ppm jika dianalisis langsung tanpa perlakuan, kemudian dibandingkan dengan proses perlakuan penyimpanan selama 7 hari, terlihat pada Gambar 2.

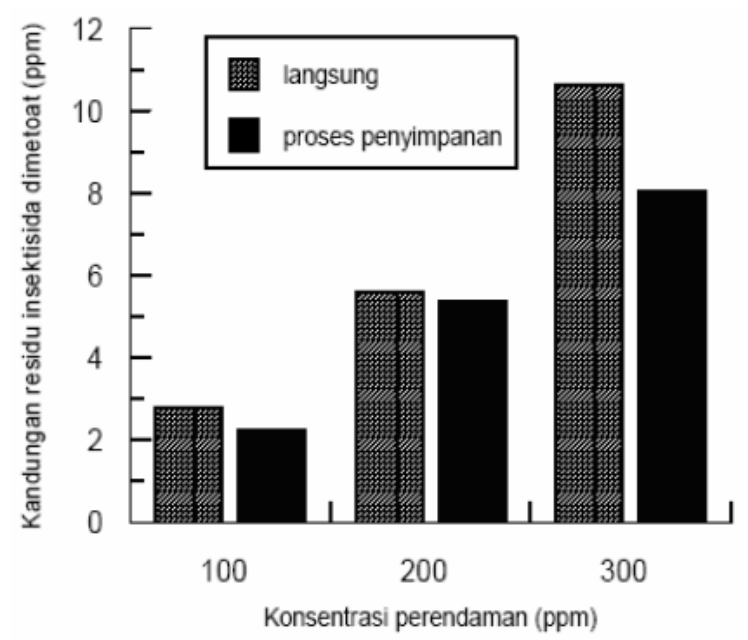

Gambar 2. Perbedaan Residu Insektisida Dimetoat Pada Perlakuan Langsung dan Penyimpanan

Pada Gambar 2 terlihat bahwa penyimpanan cabai merah pada suhu $5{ }^{\circ} \mathrm{C}$ selama 7 hari dapat menurunkan kandungan residu insektisida. Pada cabai merah dengan perendaman $100 \mathrm{ppm}$, residu insektisida mengalami penurunan 19,06\%, dari 2,78 ppm menjadi $2,25 \mathrm{ppm}$, Pada perendaman $200 \mathrm{ppm}$ terjadi perbedaan residu dari 5,59 ppm menjadi 5,37 ppm (berkurang 3,94\%), sedangkan pada perendaman $300 \mathrm{ppm}$ terjadi perbedaan residu dari 10,61 ppm menjadi 8,05 ppm (berkurang 24,13\%). Hal ini disebabkan karena dimetoat adalah senyawa organofosfat yang mempunyai waktu paruh (T1/2) yang sangat singkat sekitar lebih kurang 20-30 hari. ${ }^{[5]}$. Dengan demimkian penyimpanan pada suhu $5{ }^{\circ} \mathrm{C}$ akan terjadi pengurangan sebesar $<25 \%$. Residu dimetoat pada cabai dengan perendaman $300 \mathrm{ppm}$ terlihat lebih tinggi baik tanpa perlakuan (langsung) 
maupun dengan perlakuan penyimpanan. Hal ini disebabkan karena pada perendaman dengan konsentrasi yang tinggi maka penyerapan dimetoat terhadap cabai juga semakin tinggi.

Perbandingan kandungan dimetoat pada pada cabai merah yang dianalisis segera setelah perlakuan perendaman dengan setelah perlakuan iradiasi, baik pada dosis 0,$5 ; 1,0$; dan 1,5 kGy dapat dilihat pada Gambar 3.

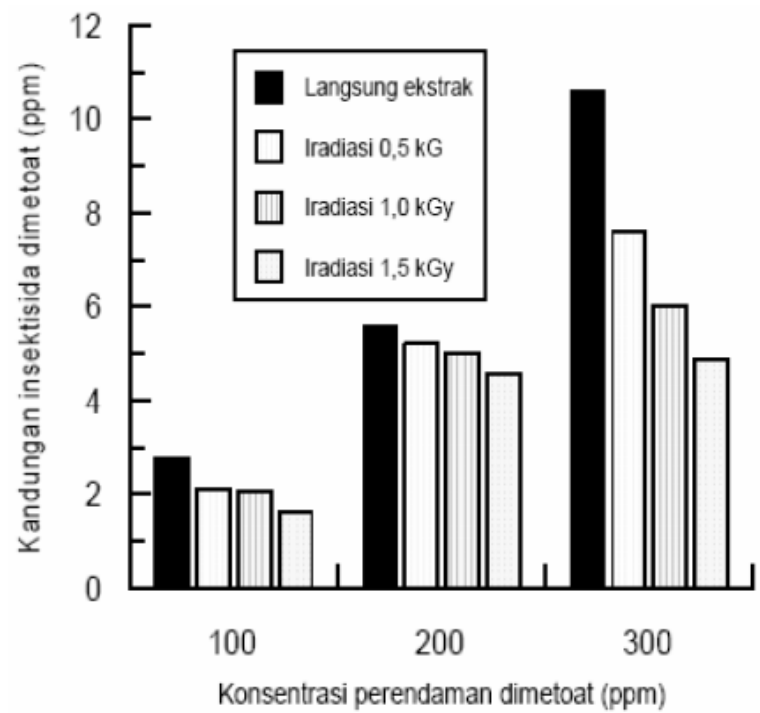

Gambar 3. Perbedaan Residu Insektisida Dimetoat Pada Perlakuan Langsung dan Proses Iradiasi Dengan Dosis 0,5; 1,0; dan 1,5 kGy

Pada Gambar 3 terlihat bahwa pada perendaman dengan dimetoat pada konsentrasi $100 \mathrm{ppm}$, terjadi penurunan residu yang signifikan dari 2,78 ppm menjadi 2,09 ppm setelah diiradiasi dengan sinar- $\gamma$ dengan dosis $0,5 \mathrm{kGy}$. Iradiasi dengan dosis 1,0 kGy menurunkan residu dimetoat menjadi 2,07 ppm. Antara perlakukan rradiasi pada dosis 0,5 dan $1,0 \mathrm{kGy}$ tidak terdapat perbedaan yang nyata. Penurunan kadar residu dimetoat pada cabai terlihat sangat signifikan setelah perlakuan iradiasi pada dosis $1,5 \mathrm{kGy}$, yaitu dari 2,78 ppm menjadi 1,62 ppm. Hal ini disebabkan pada dosis 1,5 kGy insektisida dimetoat sudah mulai terurai dan yang tersisa sudah hampir mendekati 50\%. Seperti diketahui bahwa titik leleh dimetoat adalah antara $45-48{ }^{\circ} \mathrm{C}$, sedangkan proses radiasi adalah suatu proses pemanasan di atas $100{ }^{\circ} \mathrm{C} .^{[5]}$

Jika dilihat penurunan insektisida akibat irradiasi sinar- $\gamma$ dengan dosis 0,5 ; 1,0 ; dan $1,5 \mathrm{kGy}$ yang dibandingkan dengan residu pada perlakuan perendaman awal dapat dilihat pada Gambar 4. 


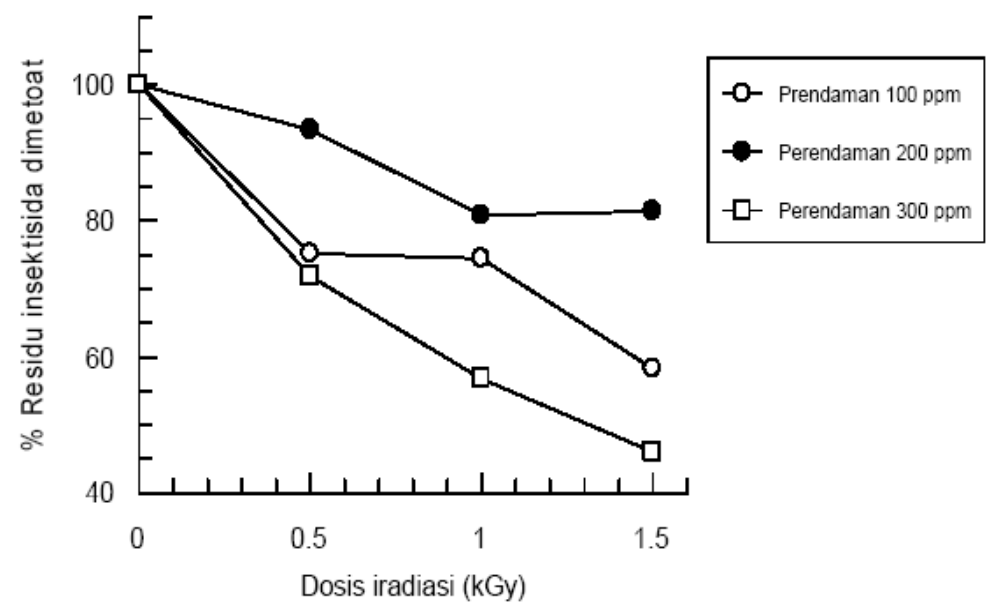

Gambar 4. Persen Penurunan Insektisida Dimetoat Akibat Iradiasi Sinar Gamma Dibandingkan dengan Residu Awal Setelah Perendaman

Gambar 4 menunjukkan bahwa iradiasi dapat menurunkan kandungan residu insektisida dimetoat pada cabai. Perlakuan iradiasi dosis $0,5 \mathrm{kGy}$ pada cabai yang direndam dengan insektisida 100 ppm,menurunkan kadar residu menjadi 75,18 \%; pada dosis $1,0 \mathrm{kGy}$ menjadi $74,46 \%$ dan pada $1,5 \mathrm{kGy}$ menjadi $59,27 \%$. Pada perendaman $200 \mathrm{ppm}$, terjadi penurunan setelah iradiasi menjadi 93,39\% jika di irradiasi dengan dosis 0,5 kGy; 89,90\% pada dosis 1,0 kGy; dan 81,43\% pada dosis 1,5 kGy. Pada perendamanan 300 ppm, terjadi penurunan menjadi $71,82 \%$ setelah diiradiasi dengan dosis $0,5 \mathrm{kGy} ; 56,74 \%$ setelah irradiasi dengan dosis 1,0 kGy; dan 46,0 \% setelah iradiasi dengan dosis 1,5 kGy.

Berdasarkan hasil yang diperoleh terlihat bahwa iradiasi sinar- $\gamma$, baik pada dosis 0,$5 ; 1,0$ maupun 1,5 kGy dapat menurunkan kandungan residu insektisida dimetoat pada cabai merah.

\section{KESIMPULAN DAN SARAN}

Dari penelitian simulasi yang dilakukan, maka dapat diambil kesimpulan bahwa residu insektisida dimetoat pada cabai merah keriting dapat dikurangi sampai \pm $60 \%$ dari residu awal (sebelum di iradiasi) dengan perlakuan iradiasi sinar- $\gamma$. Dengan demikian, iradiasi gamma pada perlakuan karantina cabai merah, disamping dapat dipakai untuk mengawetkan sayuran dan membunuh hama serta penyakit tanaman yang dikandungnya, juga dapat menurunkan residu insektisida yang terkandung pada cabai tersebut. Hal ini dapat dianggap sebagai dampak positip yang menguntungkan dari perlakuan karantina dengan sinar gamma, yang mungkin tidak dimiliki oleh perlakuan karantina dengan cara lain. 


\section{UCAPAN TERIMA KASIH}

Pada pelaksanaan penelitian ini, kami mengucapkan terima kasih kepada. Elida Djabir, Patuan Sitorus dan Marsongko yang telah meluangkan waktunya dalam membantu pelaksaan penelitian ini terutama pada penggunaan alat Kromatografi Gas.

\section{DAFTAR PUSTAKA}

1. MAHA M., 1985, "Prospek Penggunaan Tenaga Kerja Nuklir dalam Bidang Teknologi Pangan”, Buletin, Batan, Jakarta, hal. 19-28 p.

2. BAKRI, A., N. HEATHER, J. HENDRICHS, and I. FERRIS, 2005, "Fifty Years of Radiation Biology in Entomology" : Lesson Learned from IDIDAS. Annals of the Entomological Society of America, 98 (1) : 1-12 p.

3. BURDITT, A. K. SHARP, J.L. and G.J. HALLMAN (Edit.), 1994, Quarantine Treatments for Pests of Food Plants, Westview Press. Boulder San Fransisco Oxford, $101-119 \mathrm{p}$.

4. WHO. "Food Irradiation - Skay's the Limit. Press Release WHO/68", 19 September 1997. $2 \mathrm{p}$.

5. VOS, J.G.M., 1994, "Pengelolaan Tanaman Terpadu pada Cabai (Capsicum spp.) di Dataran Tropis". Percetakan Bentang Bandung, 194 p.

6. KALSHOVEN. L.G.E.,1981, The Pests of Crops in Indononesia, PT. Ichtiar baru van Hoeve, Jakarta, 7001 p.

7. ANONIM, 1996, Farm Chemical Hand Book, p. C136

8. ANONIM, 2004, "Pedoman Pengujian Residu Pestisida Dalam Hasil Pertanian, Komisi Pestisida DirJen Bina Produksi Tanaman Pangan DepTan”, Jakarta, hal 133-136.

9. TRUBUS. Edisi Oktober 2003.

10. SHARP, J.L. and G.J. HALLMAN, 1994, Quarantine Treatments for Pests of Food Plants, Westview Press., Boulder San Fransisco Oxford $101-119$ p. 
